\title{
THE INFLUENCE OF SPRING GRAZING MANAGEMENT ON PASTURE QUALITY
}

B. M. Butler and A. C. P. Chu

Agronomy Department, Massey University

Abstract

Six grazing treatments, consisting of an intensity comparison (hard, medium and lax) at a 14-day regrowth interval, and a frequency comparison (regrowth intervals of 7, 14, 21 and 26 days) at thb medium intensity, were imposed over 12 weeks during spring (treatment period). Subsequent pasture performance was assessed over a further 12 weeks during summer (post-treatment period).

By the end of the treatment period two groups of wards were apparent. Compared with the other wards. Lax and Medium wards at regrowth intervals of 21 and 26 days were characterised by greater total. green, ryegrass reproductive stem and dead herbage mass and lower proportion of leaf. During the post-treatment period reproductive stem senesced and these wards contained greater levels of dead herbage. These wards also had lower leaf accumulation during the treatment period, though leaf accumulation was lower only on lax grazed wards during the post-treatment period.

On high-fertility, ryegrass-dominant pastures hard grazing was not required to maintain pasture quality, as this occurred also under the medium grazing intensity (residual sward height $6-6 \mathrm{~cm}$ ) provided the interval between grazing was 14 days or less (pregrazing sward height of $20 \mathrm{~cm}$ ).

It may be expected that herbage intake and animal performance on lax and infrequently $(21$ and 26 days) grazed swards would be reduced because of both lower leaf accumulation and greater dead herbage mass especially over the summer.

Keywords: Pasture quality, sward characteristics, grazıng frequency, grazing intensity, leaf accumula tion, herbage mass.

\section{INTRODUCTION}

TD be meaningful pasture quality must be defined in terms of those sward characteristics which influence herbage intake, diet selection and, ultimately, the individual performance of grazing animals.

Quantity and type of leaf (lamina) and distribution of leaf, grass reproductive stem and dead herbage within the sward canopy exert a major influence on herbage intakes and animal performance (Hodgson 1982).

Grazing management during spring has a large influence on the relative yields of herbage components and therefore pasture quality over spring and summer (Korte 1981; Sheath et a/. 1984). Previous research has highlighted the need for a compromise between lax grazing to maximise immediate animal performance and hard grazing to maintain pasture quality. However, most work has concentrated on the extremes of grazing frequency and intensity, and Korte (1981) recognised that further work was required "to establish how stemmy swards can become before the advantages of leafy swards are lost".

The trial reported here was conducted to examine the influence of spring grazing intensity and frequency on pasture quality with particular emphasis on an intermediate grazing intensity and a range of grazing frequencies which are commonly used on farms during spring and summer.

\section{METHODS}

The trial was conducted on a ryegrass/white clover pasture at Massey University, Palmerston North. There were six grazing treatments comparing three grazing intensities: $\operatorname{Hard}(\mathrm{H})$, Medium (M) and Lax (L) with residual leaf mass of approximately 150, 450 and 700 $\mathrm{kg} \mathrm{DM} /$ ha, at a 14-day regrowth interval (designated $\mathrm{H} 14$, Ml4 and L14 respectively), and four frequencies at the medium level of defoliation at 7, 14, 21 and 28-day regrowth intervals 
(designated M7, M14, M21 and M28 respectively, M14 being the common treatment across both frequency and intensity).

There were four replicates and the plots, each $180 \mathrm{~m}^{2}$ were grazed with sheep over one day. There were two periods of measurement. The grazing treatments were compared over an 84-day (12-week) "treatment" period from September 24 (day 0) to December 16 (day 83). At the end of the treatment period all plots were grazed to a residual leaf mass of $150 \mathrm{~kg}$

DM/ha over two days. Pastures were then assessed over an 84-day "post treatment" period consisting of two grazings to common residual leaf mass of approximately $450 \mathrm{~kg}$ DM/ha on 21 January 1984 (day 119) and 10 March 1984 (day 168).

At each grazing pre- and post-grazing herbage mass and herbage components were measured and the accumulation of herbage components were calculated. Details of measurement techniques are presented elsewhere (Butler 1986).

\section{RESULTS}

The mass of herbage components before grazing on days 83,119 and 168 is shown in Fig. 1. The accumulation of green and total herbage during the pre- and post-treatment periods is given in Table 1 and that of the leaf, reproductive stem and dead stem herbage components in Figure 2.
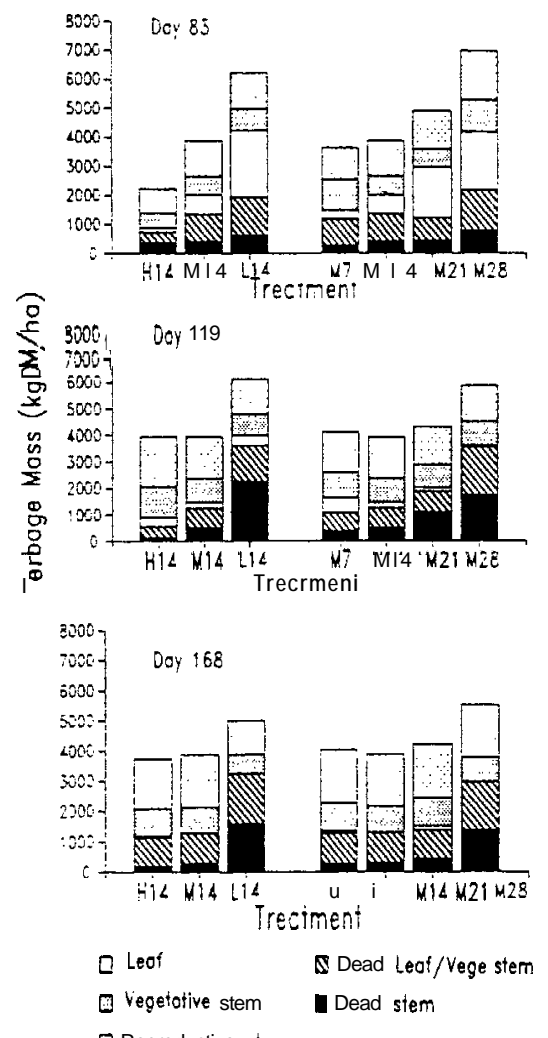

Figure 1: Pregrazing herbage mass components on days 83,119 and 168.

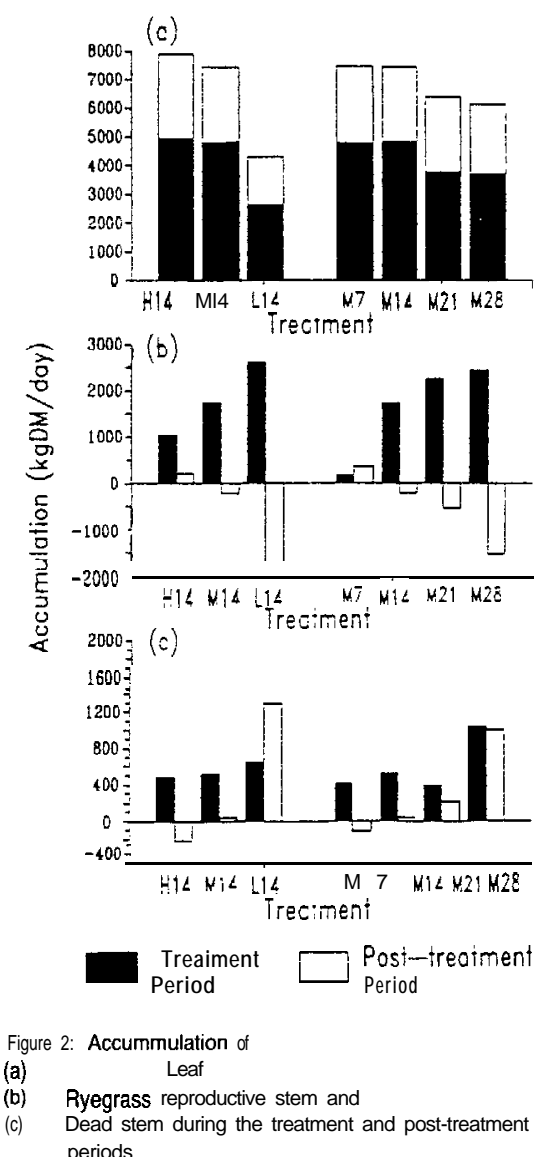


Leaf

Over the whole trial differences in leaf mass (Fig. 1) between treatments were almost entirely due to the grazing intensity and frrequency. However, as can be seen in Fig. 1, the proportion of leaf in lax and infreuently grazed swards (L14, M21 and M28) was reduced during much of the trial because of changes in the other sward components.

Leaf accumulation during the treatment period (Figure 2a) was reduced $47 \%$ by lax grazing (L14), and $22 \%$ by infrequent grazing (M21 and M28) compared to more intense and frequent grazing (H14, M7 and M14). During the post-treatment period lax grazing over spring resulted in lower leaf accumulation than under hard $(42 \%)$ or medium $(35 \%)$ spring grazing. There were no significant differences between the four frequency treatments.

\section{Grass reproductive stem and dead herbage}

By the end of the treatment period lax and infrequent grazing (L14, M21 and M28) resulted in swards of greater live ryegrass reproductive stem and dead herbage mass compared with more intense and frequent grazing (H14, M7 and M14) (Fig. 1). However, there were no significant differences in grass reproductive stem (Figure 2b), dead stem (Figure 2c) or dead leaf (Butler 1986) accumulation during the treatment period, though the former was much greater under lax and infrequent grazing (M21, M28 and L14) than on the other swards.

Over the post-treatment period live ryegrass reproductive stem senesced, resulting in much greater dead herbage mass (Fig. 1), lower ryegrass reproductive stem accumulation (Fig. 2b) and greater dead stem accumulation (Fig. 2c) on lax and infrequently grazed swards.

\section{Green and total herbage}

Throughout the trial both green and total herbage mass reflected differences in the mass of ryegrass reproductive stem and dead stem (Fig. 1).

During the treatment period there were no significant differences in green or total herbage accumulation (Table 1). Over the post-treatment period large differences in both green and total herbage accumulation (Table 1) were largely the result of differences in the accumulation of ryegrass reproductive stem and dead stem (Fig. $2 b$ and $2 c$ respectively).

Table 1. Effect of grazing intensity and frequency on the accumulation of green and total herbage ( $\mathrm{kg} \mathrm{DM} /$ day) during the treatment and post-treatment periods

\begin{tabular}{lccccccc}
\hline & H14 & M14 & L14 & $\begin{array}{c}\text { Treatment } \\
\text { M7 }\end{array}$ & M14 & M21 & M28 \\
\hline $\begin{array}{l}\text { Treatment } \\
\text { Green } \\
\text { Total }\end{array}$ & $6950 \mathrm{a}$ & $6250 \mathrm{a}$ & $6540 \mathrm{a}$ & $6490 \mathrm{a}$ & $6250 \mathrm{a}$ & $6510 \mathrm{a}$ & $\begin{array}{l}7000 \mathrm{a} \\
\text { Post-treatment }\end{array}$ \\
$\begin{array}{l}\text { Green } \\
\text { Total }\end{array}$ & $8580 \mathrm{a}$ & $7490 \mathrm{a}$ & $7740 \mathrm{a}$ & $7870 \mathrm{a}$ & $7490 \mathrm{a}$ & $7480 \mathrm{a}$ & $9080 \mathrm{a}$ \\
& & & & & & & \\
& $4360 \mathrm{~d}$ & $3070 \mathrm{~cd}$ & $270 \mathrm{a}$ & $3730 \mathrm{Cd}$ & $3070 \mathrm{~cd}$ & $2810 \mathrm{bc}$ & $1540 \mathrm{ab}$ \\
& $4900 \mathrm{a}$ & $3690 \mathrm{a}$ & $2400 \mathrm{a}$ & $4230 \mathrm{a}$ & $3690 \mathrm{a}$ & $3440 \mathrm{a}$ & $2770 \mathrm{a}$ \\
\hline
\end{tabular}

values with the same letter are not significantly different $(P<0.05)$.

\section{DISCUSSION}

The results presented here clearly demonstrate the effect of grazing frequency and intensity on pasture quality, particularly the quantity and distribution of leaf, live ryegrass reproductive stem and dead herbage.

Sheath et al. (1984) stressed the importance of a compromise between high feed offer and control of pasture quantity and quality, and well-timed hard grazing has frequently been recommended as management necessary to achieve this (Korte 1982).

The results of this trial are in close agreement with those of others (eg Korte 1981): compared with hard grazing, lax and/or infrequent spring grazing results in swards with a greater mass of ryegrass reproductive stem and dead herbage, and lower subsequent leaf accumulation. 
However leafy, high quality swards also resulted from medium grazing intensities (residual sward height of $6-8 \mathrm{~cm}, 1400-1600 \mathrm{~kg}$ green DM/ha), provided the interval between grazing was not too long (14 days or less, pregrazing sward height of less than $20 \mathrm{~cm}$, 2700-3000 kg green DM/ha). There is good evidence that the medium grazing intensity should also be sufficient to promote high levels of performance in grazing stock (B. M. Butler unpubl. data; Sheath \& Bryant 1984).

Therefore, on high fertility ryegrass-dominated pastures, hard grazing during spring is not required as there is in fact little compromise in spring grazing management to maintain productive, high quality pastures and achieve high stock performance.

During spring and early summer lax or very infrequent grazing may have little influence on stock performance while pasture growth (especially leaf) remains higher than stock requirements. This is because herbage intakes and stock performance appear to be directly related to the level of leaf but little influenced by the level of reproductive grass stem, in the pasture (Butler et al. 1987; B. M. Butler unpubl. data). However, dead herbage may have a large negative effect (Butler et al. 1987). Therefore, probably only when grass reproductive stem dies and/or leaf mass declines because of lower leaf accumulation over summer, will herbage intakes and animal performance be affected.

In many trials the effect of grazing management on herbage production is measured in terms of the effect on green and/or total herbage accumulation (Korte 1981; Sheath et al. 1984). The results of the present trial suggest that green and total herbage accumulation will not adequately represent the production of herbage available to grazing stock. Throughout the trial green and total herbage accumulation were influenced mostly by the accumulation of grass stem and dead herbage respectively, rather than leaf accumulation. Unless stock are hard grazed the former are left largely uneaten and senesce without contributing to stock performance. Therefore, to adequately estimate herbage production available to grazing stock leaf accumulation should be measured.

Little success has so far been achieved in developing useful management models over the late spring and summer because of difficulties in adequately describing pasture quality and its affects on stock performance. It is susggested that this may be achieved by taking into account the effects of grazing management on herbage components, particuarly leaf, grass reproductive stem and dead herbage, and the influence of these components and pasture composition on stock performance. There is, however, a need for further detailed research into these relationships.

\section{References}

Butler B.M. 1966. The effect of grazing intensity and frequency during spring and early summer on the sward characteristics of a ryegrass-white clover pasture. MAgrSc Thesis, Massey University.

Butler B.M., Hoogendorn C.J., Richardson M.A. 1967. The influence of leaf allowance on animal performance in late spring and summer. The 4th AAAP Animal Science Congress Proceedings. p. 174.

Hodgson J. 1962. Influence of sward characteristics on diet selection and herbage intake by the grazing animal. In Hacker J.B. (Ed,) Nutritional limits to animal production from pasture.5 Commonwealth Agricultural Bureaux.

Korte C.J. 1981. Studies of late spring grazing management in perennial ryegrass dominant pasture. PhD Thesis, Massey University.

Korte C.J. 1962. Grazing management of perennial ryegrass/white clover pasture in late spring. Proceedings NZ Grass/and Association 43: 80-84

Sheath G.W.. Webby R.W.. Pengally W.J. 1964. Management of late spring-early summer pasture surpluses in hill country. Proceedings NZ Grass/and Association 45: 199-206.

Sheath G.W., Bryant A.M. 1964. Integrating the components of pastoral production: What have we learnt from grazing management experiments? NZ Agricultural Science 18(3): t 47. 